\title{
Anterior Optic Pathway Compression Due to Internal Carotid Artery Aneurysms: Neurosurgical Management and Outcomes
}

\author{
Wonhyoung Park, , Jung Cheol Park, ${ }^{a}$ Kyunghwa Han, ${ }^{\mathrm{b}}$ Jae Sung Ahn, ${ }^{\mathrm{a}}$ Byung Duk Kwun ${ }^{\mathrm{a}}$ \\ ${ }^{a}$ Department of Neurosurgery, University of Ulsan College of Medicine, Asan Medical center, Seoul, Korea \\ ${ }^{\mathrm{b}}$ Biostatistics Collaboration Unit, Gangnam Medical Research Center, Yonsei University College of Medicine, Seoul, Korea
}

Background and Purpose Compression of the anterior optic pathway results in visual deficits that can lead to the detection of unruptured aneurysms in the internal carotid artery (ICA). The general types of treatment modalities for aneurysms and visual deficits include surgery and endosaccular coiling. This study retrospectively analyzed and compared the resolution of visual deficits following surgery or endosaccular coiling.

Methods We reviewed data on 33 patients with unruptured ICA aneurysms who presented with visual field deficits caused by mass effects over the anterior optic pathway. Statistical analyses were performed to identify the variables associated with the recovery of visual symptoms.

Results Eighteen patients underwent aneurysm clipping, 2 underwent bypass surgery with endovascular trapping, and 2 underwent endovascular trapping without bypass surgery (group A). Ten patients received endosaccular coiling (group B). The visual outcomes included the following: in group A, 17 patients (73.9\%) demonstrated improvement and 6 patients (26.1\%) demonstrated no changes or worse outcomes; in group B, 2 patients (20.0\%) demonstrated improvement and 8 patients $(80.0 \%)$ demonstrated no changes or worse outcomes. Group A was associated with a higher rate of favorable outcome than group B $(P=0.007)$. According to the multivariate analysis, treatment without endosaccular coiling (group A) was the only variable significantly associated with improvement of visual outcome $(P=0.005 ; \mathrm{OR}=28.523 ; 95 \% \mathrm{Cl}=2.683-303.171)$.

Conclusions Treatment modality was the only predictor of improvement in visual deficits. Treatment without endosaccular coiling resulted in visual improvement significantly more often in comparison with endosaccular coiling.

Keywords Aneurysm; Coil; Embolization; Internal carotid artery; Surgery; Visual symptom

\author{
Correspondence: Jung Cheol Park \\ Department of Neurosurgery, Asan \\ Medical Center, 88 Olympic-ro 43-gil, \\ Songpa-gu, Seoul 05505, Korea \\ Tel: +82-2-3010-3563 \\ Fax: +82-2-476-6738 \\ E-mail: neurosg@amc.seoul.kr
}

Received: March 22, 2015

Revised: July 16, 2015

Accepted: August 3, 2015

The authors have no financial conflicts of interest.

\section{Introduction}

Cranial nerve deficit is a clinical condition that can lead to the detection of unruptured intracranial aneurysm (UIA). The International Study of Unruptured Intracranial Aneurysms Inves- tigators reported that $15.4 \%$ of patients with UIAs present with cranial nerve deficits, ${ }^{1}$ and other studies report incidences of $2.2 \%$ and $8.8 \%{ }^{2,3}$ Oculomotor nerve palsy related to posterior communicating artery aneurysm is one of the most common cranial nerve deficits caused by UIAs, ${ }^{2,49}$ but, less commonly, 
visual deficits related to UIAs that originate from the internal carotid artery (ICA) have also been reported. ${ }^{5,9-14}$

Because the intradural course of the ICA is close to the anterior optic pathway, some UIAs that arise in this location result in some degree of visual deficit. ${ }^{10,11,14}$ The possible mechanisms for visual deficits include the direct mass effects of the aneurysm on the anterior optic pathway, compression of the optic nerve against the bony structure by the aneurysm, and compromised vascular supply to the anterior optic pathway. ${ }^{10,12,14}$

Neurosurgical management should be considered because the risk of rupture is higher in patients with symptomatic UIAs than asymptomatic UIAs, and management can alleviate symptoms and prevent rupture. ${ }^{10,14-16}$ There are two general types of treatment modalities for UIAs: surgery and endosaccular coiling. Both of these treatment modalities effectively prevent UIA rupture. However, few studies report which treatment modality more effectively alleviates the visual deficits caused by UIAs that arise in the ICA. In our current study, we retrospectively analyzed and compared the results of treating UIAs that arose in the ICA following surgery or endosaccular coiling.

\section{Methods}

\section{Study population}

This study was approved by the Institutional Review Board before data collection. We retrospectively reviewed patients with UIAs in the ICA who were treated at our institution between January 2009 and March 2014. Patients were assessed according to the following inclusion criteria: 1 ) presented with visual dysfunction and 2) compressive optic neuropathy was confirmed using high-resolution magnetic resonance image (MRI) and ophthalmologic examination. Patients with other possible causes, such as cerebral infarction, intracerebral hemorrhage, tumorous lesions, or ophthalmologic causes (e.g., glau-
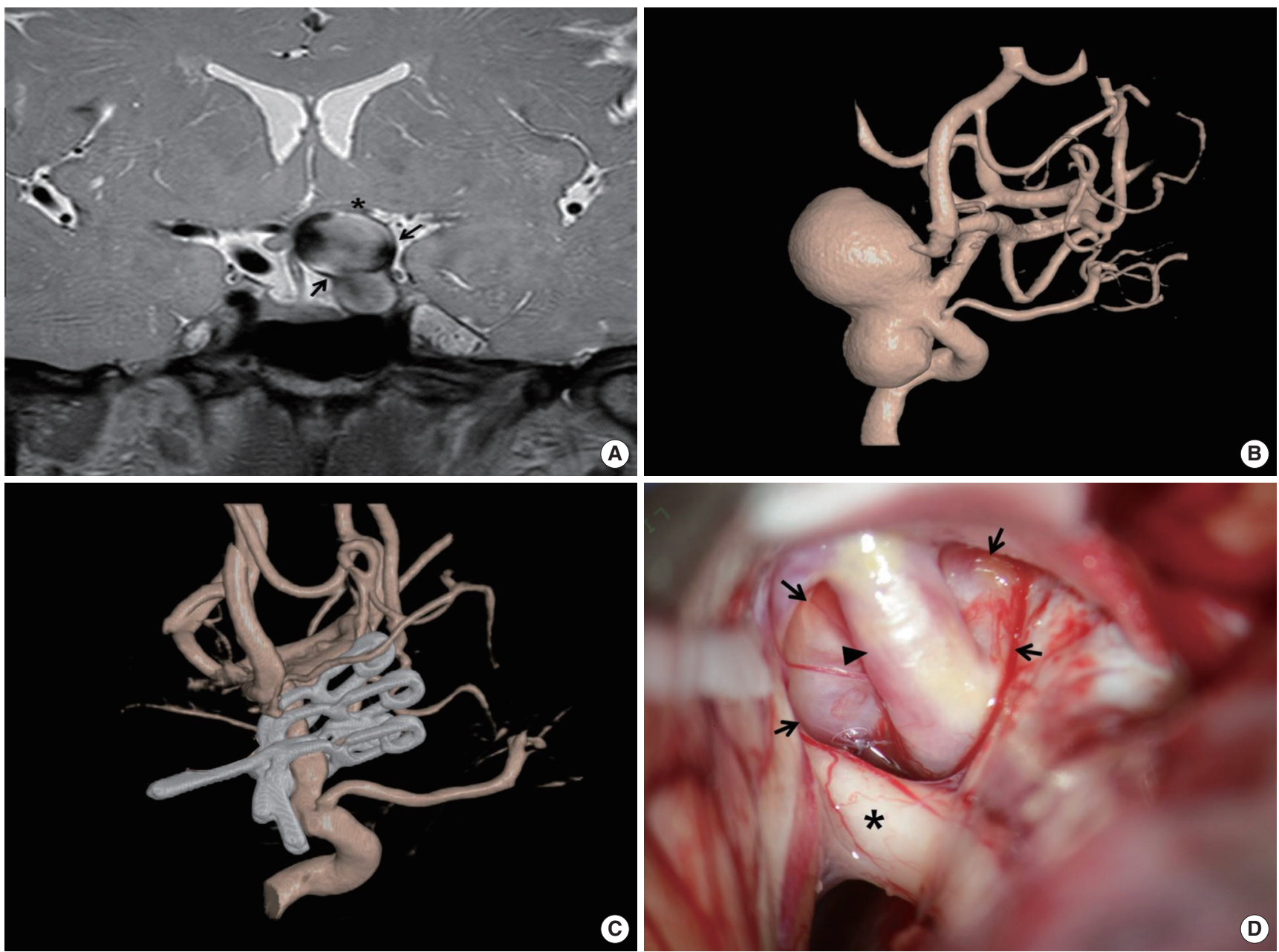

Figure 1. (A) High-resolution magnetic resonance image (MRI) showing optic chiasm compression due to a giant aneurysm, which is located in the ophthalmic segment of the left internal carotid artery (ICA). (B) Three-dimensional (3D) angiography of the aneurysm. (C) Intraoperative photograph of the aneurysm. (D) Direct neck clipping was performed with suction decompression technique after extradural anterior clinoidectomy. 3D angiography after microsurgery; aneurysm (black arrows), left ICA (black large arrow head), and optic nerve $\left(^{*}\right)$. 
coma, cataracts), were excluded. Among the patients with UIAs in the ICA, 33 patients met the inclusion criteria. Visual field examinations were performed preoperatively and $\geq 6$ months after treatment. Patient characteristics, aneurysm size, location, radiological features, degree and involved location of visual dysfunction, and changes in visual symptoms after treatment were analyzed. Visual symptoms were mainly specified according to visual field impairments, and deterioration in visual acuity was only used as the reference criteria. To assess the degree of visual dysfunction, we scored the involved quadrants on a scale of 1-8 (i.e., the total number of the quadrants that demonstrated visual field defects). According to the patterns of the visual field defects and the results of high-resolution MRI, the involved locations were categorized as present in the optic nerve, chiasm, or tract.

\section{Treatment modalities}

All patients were treated using surgical clipping or endovascular treatment according to interdisciplinary consensus. Direct neck clipping with or without suction decompression technique was performed on 18 patients (Figure 1). Five patients received endovascular parent artery trapping without endosaccular embolization. Extracranial-intracranial bypass surgery was performed on 3 of 5 patients before trapping due to insufficient collateral blood flow (Figure 2). These 23 patients were assigned to treatment group A (non-endosaccular embolization group), which reduces aneurysmal pulsatility and mass effects. The oth- er 10 patients received endosaccular embolization with or without the stent-assisted technique and were assigned to treatment group B, which reduces aneurysmal pulsatility without removing mass effects (Figure 3 ).

\section{Clinical and visual follow-up}

Outcomes were stratified according to treatment group. The mean \pm standard deviation [SD] clinical follow-up period was $21.4 \pm 11.6$ months (median $=22$ months; range $=6-45$ months). The mean follow-up period for visual field examinations was $10.4 \pm 6.0$ months (median $=10$ months; range $=6-30$ months). Treatment-related complications were also assessed during the follow-up period.

\section{Statistics analysis}

Statistical analyses were conducted using standard commercial software (IBM SPSS statistics for windows, Version 20.0, Armonk, NY: IBM Corp.). Fisher's exact test was used for categorical variables, and Student's $t$ test was used for continuous variables in order to compare characteristics and treatment outcomes of group A and B. Student's $t$ test also used for continuous variables in order to compare characteristics of favorable outcome (improved) group and unfavorable outcome (stationary and aggravated) group. In these studies, $P<0.05$ is considered statistically significant.

A multivariate analysis was performed to find independent
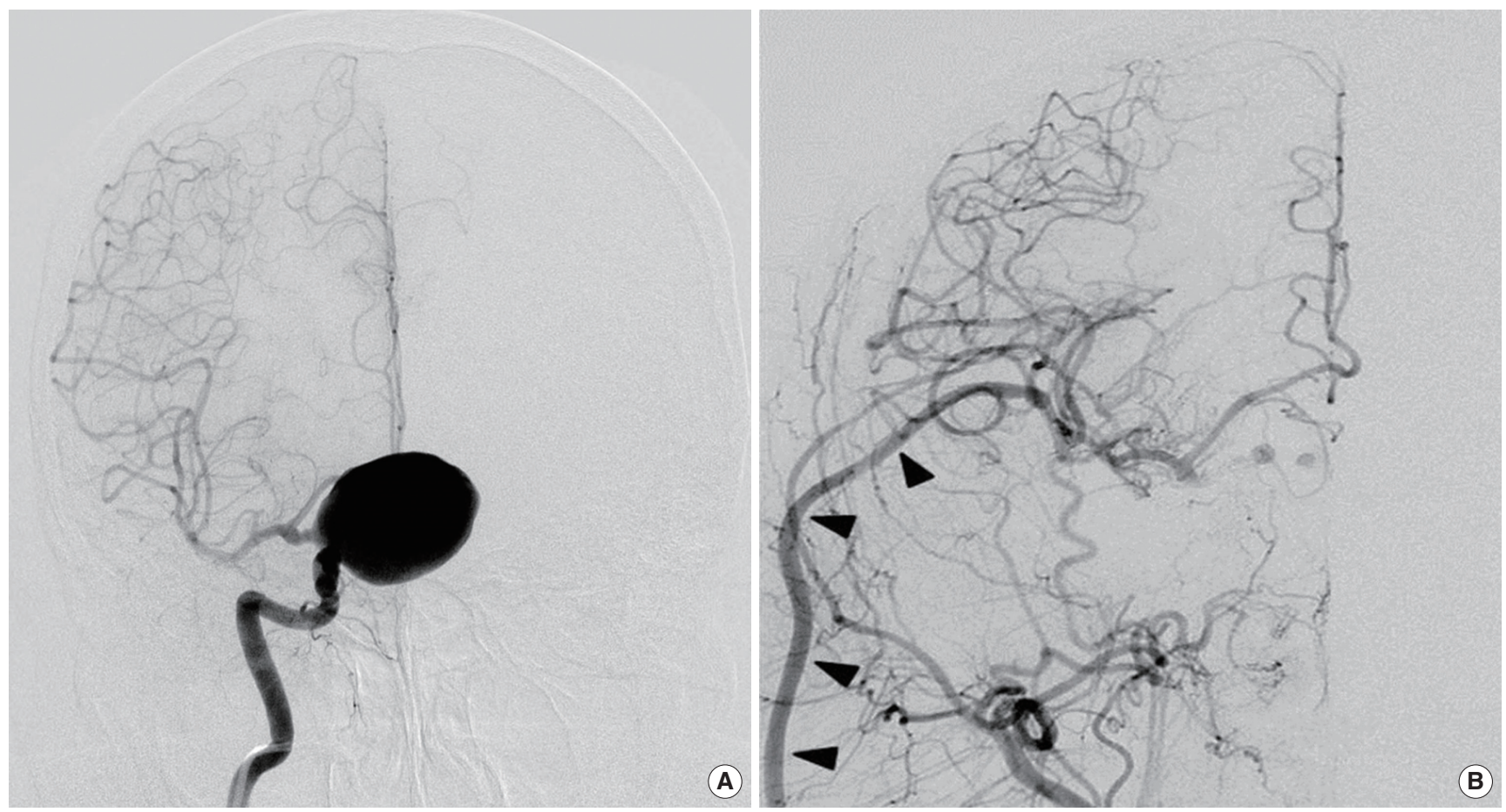

Figure 2. (A) Transfemoral cerebral angiography showing a giant aneurysm located in the ophthalmic segment of the right internal carotid artery (ICA). (B) Endovascular parent artery trapping was performed after high flow bypass surgery using a radial artery graft; radial artery graft (black arrows). 

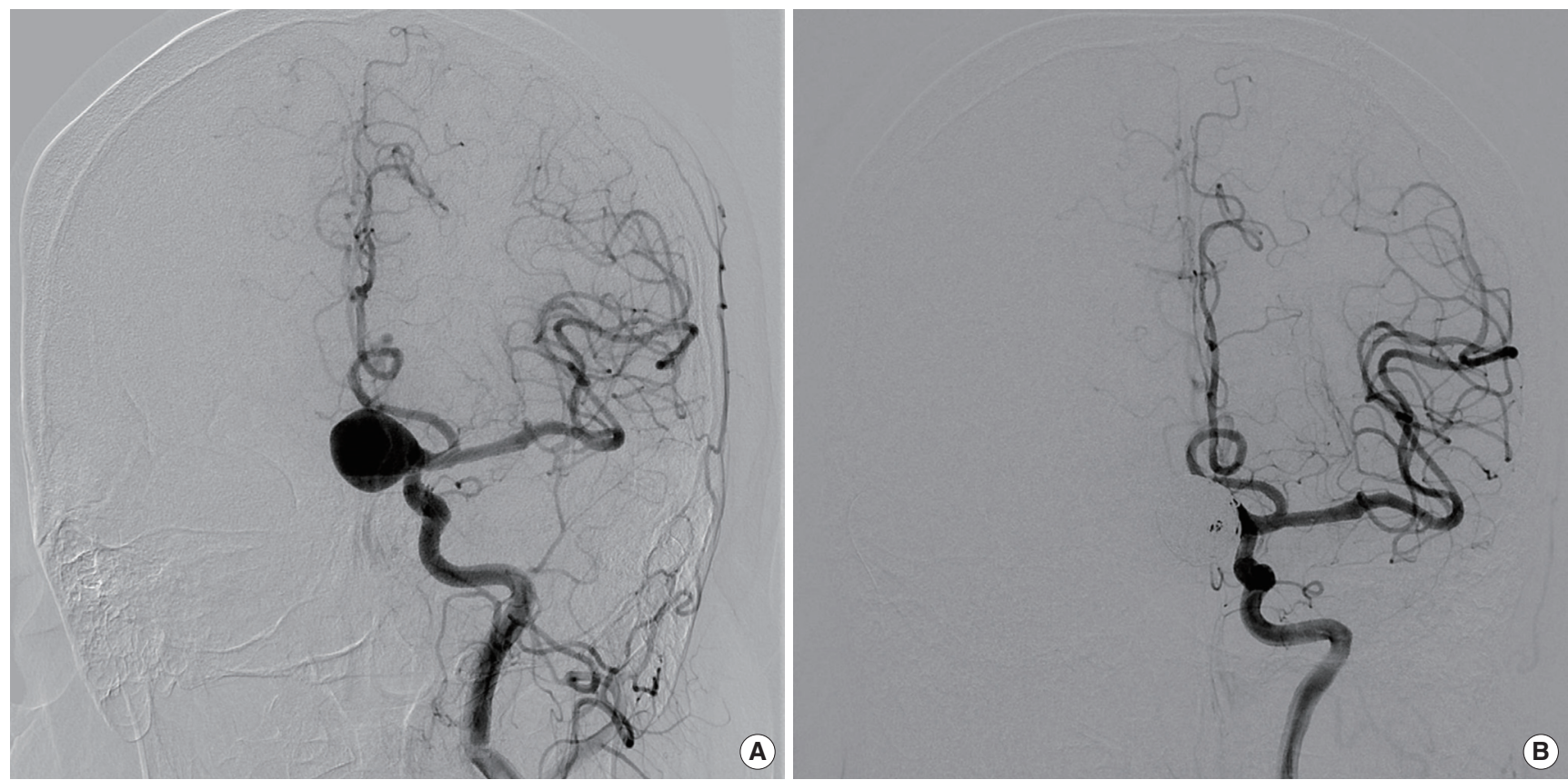

Figure 3. (A) Transfemoral cerebral angiography showing a large aneurysm in the left ophthalmic segment of the internal carotid artery (ICA). (B) Transfemoral cerebral angiography after stent-assisted endosaccular coil embolization showing the near-complete occlusion of the aneurysm.

predictors of favorable outcome using logistic regression analysis. Variables with $P<0.05$ according to the univariate analysis, and variables that affected visual outcomes according to previous studies (e.g., aneurysm size, symptom duration, intra-aneurysmal thrombosis) were included in the multivariate analysis. ${ }^{14,17}$

\section{Results}

\section{Characteristics of the patients and aneurysms}

The study population consisted of 5 men and 28 women ( mean age $=60.3 \pm 8.7$ years; range $=43-77$ years). The maximum diameter of the aneurysms ranged between $7.1-42 \mathrm{~mm}$ $($ mean $=19.8 \pm 8.7 \mathrm{~mm})$. Twenty-six aneurysms $(78.8 \%)$ were larger than $10 \mathrm{~mm}$ and, among these, 6 aneurysms (18.2\%) were classified as giant aneurysms $(>25 \mathrm{~mm}$ ). Almost all aneurysms (31 of 33) were located in the ophthalmic segment of the ICA. Only 2 giant aneurysms that were located in the cavernous segment of the ICA presented with visual disturbance. The mean number of involved quadrants was $3.4 \pm 1.7$ (range = 1-7), and the mean \pm SD duration of visual symptoms was $6.5 \pm 5.1$ months (range $=1-24$ months). Intra-aneurysmal thrombosis was observed in 5 patients. The sex ratio, patient age, aneurysm size, duration of visual symptoms, involved quadrant, involved location, intra-aneurysmal thrombosis and complications related to the treatment were not significantly different between treatment groups (Table 1).
Table 1. Characteristics between treatment group $A$ and $B$

\begin{tabular}{lccr}
\hline & $\begin{array}{c}\text { Group A } \\
(\mathrm{n}=23)\end{array}$ & $\begin{array}{c}\text { Group B } \\
(\mathrm{n}=10)\end{array}$ & Pvalue \\
\hline Sex (male:female) & $5: 18$ & $0: 10$ & 0.291 \\
Age (year \pm standard deviation $[S D])$ & $58.9 \pm 9.0$ & $63.7 \pm 7.3$ & 0.146 \\
Size of aneurysm (mm \pm SD) & $20.1 \pm 9.2$ & $16.0 \pm 7.1$ & 0.218 \\
Symptom duration (months \pm SD) & $6.3 \pm 5.5$ & $7.1 \pm 4.1$ & 0.669 \\
Intra-aneurysmal thrombosis $(\mathrm{n}=5)$ & $4 / 23$ & $1 / 10$ & $>0.999$ \\
Involved quadrants before treatment $(\mathrm{n} \pm \mathrm{SD})$ & $3.7 \pm 1.6$ & $2.9 \pm 1.9$ & 0.660 \\
Involved location (optic nerve: chiasm: tract) & $9: 8: 6$ & $8: 1: 1$ & 0.097 \\
Complications & $3 / 23$ & $1 / 10$ & $>0.999$ \\
\hline
\end{tabular}

The statistical analysis was performed between 2 groups using the Student $t$ test for the variables of age, size of aneurysm, symptom duration and involved quadrant; the Fisher exact test was used for the variables of sex, intra-aneurysmal thrombosis, involved location and complications. Statistical significance was assumed when the $P$ value was $<0.05$.

$\mathrm{SD}$, standard deviation; $P$ value, probability value.

\section{Treatment outcomes}

The mean follow-up period for visual field examinations after treatment was 9.6 \pm 4.0 months in group $\mathrm{A}$ in comparison with $16.1 \pm 7.5$ months in group $B(P=0.026)$. The mean numbers of involved quadrants before treatment and at the final visual field examination after treatment were $3.7 \pm 1.6$ and $2.0 \pm 2.3$ in group A in comparison with $2.9 \pm 2.0$ and $3.1 \pm 2.6$ in group B. Improvement in visual symptoms after treatment was achieved in 17 patients in group A (73.9\%) in comparison with only 2 patients in group B (20.0\%). There were no changes in the visual symptoms in 4 patients in group A (17.4\%) and 4 patients in group B 
(40.0\%). Visual symptoms are aggravated in 2 patient in group A (8.7\%) in comparison with 4 patients in group B (40.0\%). There is a significant difference of treatment outcomes between two groups ( $P=0.011$; determined using the Fisher exact test) (Table $2)$. In addition, if the treatment outcomes are categorized into two groups, favorable outcome (improved) and unfavorable outcome (stationary and aggravated), there is also a significant difference of treatment outcomes between group A and B $(P=0.007$; determined using the Fischer exact test).

\section{Treatment-related complications}

Three of 23 patients in group A (13.0\%) developed treatmentrelated complications. Two patients developed transient oculomotor nerve palsy after aneurysm clipping. The other patient with a right ICA aneurysm developed left hemiparesis 2 days after endovascular parent artery trapping following extracranial-intracranial bypass surgery. Diffusion-weighted MRI revealed multifocal acute infarctions in the right anterior and middle cerebral artery territories.

One of 10 patients in group B (10.0\%) developed left hemiparesis 1 month after performing endosaccular coiling on the right ICA aneurysm with stenting. Multifocal small infarctions and

Table 2. Treatment outcomes of visual symptoms

\begin{tabular}{lccc}
\hline & Group $\mathrm{A}(\mathrm{n}=23)$ & Group $\mathrm{B}(\mathrm{n}=10)$ & Pvalue \\
\hline Improved & $17(73.9 \%)$ & $2(20.0 \%)$ & \\
Stationary & $4(17.4 \%)$ & $4(40.0 \%)$ & 0.011 \\
Aggravated & $2(8.7 \%)$ & $4(40.0 \%)$ &
\end{tabular}

Fisher's exact test was used to perform statistical analysis. Statistical significance was assumed when the $P$ value was $<0.05$.

$P$ value, probability value.

Table 3. Univariate logistic regression for favorable outcome

\begin{tabular}{lcc}
\hline Variables & OR (95\% Cl) & $P$ value \\
\hline Female & $0.889(0.128-6.182)$ & 0.905 \\
Mean age & $0.971(0.894-1.054)$ & 0.480 \\
Age $<60$ years & $0.900(0.226-3.583)$ & 0.881 \\
Mean aneurysm size & $0.966(0.890-1.049)$ & 0.411 \\
Aneurysm size <20 mm & $1.714(0.422-6.968)$ & 0.451 \\
Mean symptom duration & $0.863(0.726-1.026)$ & 0.096 \\
Symptom duration $<6$ months & $3.086(0.734-12.981)$ & 0.124 \\
Mean involved quadrants & $0.763(0.498-1.169)$ & 0.214 \\
Involved quadrants $<4$ & $1.481(0.369-5.946)$ & 0.579 \\
Involved location & & \\
Optic nerve & $0.450(0.068-2.998)$ & 0.409 \\
Chiasm & $0.500(0.061-4.091)$ & 0.518 \\
Radiation & reference & \\
Intra-aneurysmal thrombosis & $0.139(0.014-1.418)$ & 0.096 \\
Treatment modality: group A & $11.333(1.859-69.080)$ & 0.008 \\
\hline
\end{tabular}

Statistical significance was assumed when the $P$ value was $<0.05$.

$\mathrm{Cl}$, confidence interval; $\mathrm{OR}$, odds ratio; $P$ value, probability value. decreased perfusion in the right middle cerebral artery territory were revealed using MRI. transfemoral cerebral angiography demonstrated severe stenosis in the ICA due to thrombosis in the stent. The patient underwent chemical thrombolysis using Tirofiban.

Comparisons between favorable outcome group and unfavorable outcome group, and factors predictive of improved visual symptoms

The mean follow-up period for visual field examinations after treatment was $9.5 \pm 3.7$ months in favorable outcome group in comparison with $14.3 \pm 7.4$ months in unfavorable outcome group $(P=0.033)$. And, the mean numbers of involved quadrants at the final visual field examination after treatment was $0.7 \pm 0.9$ in favorable outcome group in comparison with $4.6 \pm 2.0$ in unfavorable outcome group $(P<0.001)$. Patients with favorable outcomes presented with a mean aneurysm size of $17.8 \pm 7.7 \mathrm{~mm}$ in comparison with $20.3 \pm 10.0 \mathrm{~mm}$ among patients with unfavorable outcomes $(P=0.411)$. The mean age of the patients who achieved favorable outcomes was $59.4 \pm 8.2$ years in comparison with $61.6 \pm 9.5$ years for patients with unfavorable outcomes $(P=0.480)$. The mean symptoms duration $(5.3 \pm 5.2$ months for patients with favorable outcomes vs $8.4 \pm 4.3$ months for patients with unfavorable outcomes; $P=0.096)$ and the mean number of involved quadrants ( $3.1 \pm 1.4$ quadrants in patients with favorable outcome vs. $3.9 \pm 2.1$ quadrants in patients with unfavorable outcomes; $P=0.214$ ) were not predictive of favorable outcomes. Intra-aneurysmal thrombosis and the involved location (e.g., optic nerve, chiasm, or tract) did not demonstrate any differences between patients with favorable and unfavorable outcomes (Table 3). For the univariate analysis, the treatment modality 'group $A$ ' was identified as a variable associated with favorable outcomes $(P=0.008)$.

A multivariate analysis was performed to find independent predictors of favorable outcome. The variable, treatment modality 'group A' and variables that affected visual outcomes according to previous studies (e.g., aneurysm size, symptom duration, intraaneurysmal thrombosis) were included in the multivariate analysis. ${ }^{14,17}$ Of these variables, only the treatment modality 'group A' $(P=0.005 ; \mathrm{OR}=28.523 ; 95 \% \mathrm{CI}=2.683-303.171)$ was deter-

Table 4. Multivariate logistic regression for favorable outcome

\begin{tabular}{lcc}
\hline Variables & OR $(95 \% \mathrm{CI})$ & $P$ value \\
\hline Aneurysm size $<20 \mathrm{~mm}$ & $2.830(0.340-23.556)$ & 0.336 \\
Symptom duration $<6$ months & $3.392(0.496-23.190)$ & 0.213 \\
Intra-aneurysmal thrombosis & $0.071(0.005-1.031)$ & 0.053 \\
Treatment modality: group A & $28.523(2.683-303.171)$ & 0.005
\end{tabular}

Statistical significance was assumed when the $P$ value was $<0.05$.

$\mathrm{Cl}$, confidence interval; $\mathrm{OR}$, odds ratio; $P$ value, probability value. 
mined to be an independent and significant predictor of improvement in visual field defects caused by intracranial aneurysms (Table 4).

\section{Discussion}

\section{Anatomical consideration}

Aneurysms that cause visual deficits due to anterior optic pathway compression can arise in any portion of the circle of Willis. ${ }^{10,11,13,14,18-20}$ However, aneurysms that arise from the ICA, especially the paraclinoid ICA, are the most common cause of visual deficits caused by aneurysmal compression of the anterior optic pathway. ${ }^{10,14}$ Here, the ophthalmic segment was the most common location for UIAs that cause visual deficits. Because the ophthalmic segment of the ICA is located just below the optic nerve and optic chiasm, UIAs that arise from this location may induce mass effects on the optic pathway. In addition, these UIAs can also displace the optic nerve toward bony structures and thereby further compress the optic nerve. These direct compression mechanisms are believed to be the main cause of visual deficits. On the other hand, the blood supply to the anterior optic pathway can be diminished by a kinked ophthalmic artery, and blood flow through the small arterial branches in the parasellar or suprasellar regions can be reduced by the mass effects of the UIAs. ${ }^{10,14}$ The International Study of Unruptured Intracranial Aneurysms Investigators reported that the sizes of almost all UIAs are less than $10 \mathrm{~mm}^{1}$, but $88.5 \%$ of UIAs that caused visual deficits were larger than $10 \mathrm{~mm}$ in our study and other studies reported similar results. ${ }^{10-13}$ Large and giant aneurysms that arise from the cavernous segment are well-known causes of 3rd, 4th, 5 th, and 6th cranial nerve dysfunction. ${ }^{10,21,22}$ However, our current study and others report that giant aneurysms that arise from the cavernous segment can cause visual deficits. ${ }^{10,23,24}$

\section{Choice of treatment modality}

Several previous studies have reported that endosaccular coiling is as effective as surgical clipping for treating 3rd nerve dysfunction due to posterior communicating artery aneurysms, and reducing aneurysmal pulsatility without removing mass effects may be an important mechanism for recovering 3rd nerve function. ${ }^{2,25-28}$ Therefore, our current study also has placed emphasize on whether endosaccular coiling is as effective as surgical clipping for the treatment of visual deficits caused by aneurysms that arise from the ICA and has further focused on the mass effects of endosaccular coiling. According to our present results, patients in group $\mathrm{A}$, who achieved not only the removal of the mass effects of the aneurysm but also reduced aneurysmal pulsatility, demonstrated visual improvement significantly more often in comparison with group B patients who achieved only the reduction of aneurysmal pulsatility. Aneurysm size, symptom duration, intra-aneurysmal thrombosis, involved quadrants in the visual field, and involved location in the anterior optic pathway were not predictive of favorable outcomes. Only the treatment modality 'group A' $(P=0.005$; $\mathrm{OR}=28.523$; $95 \% \mathrm{CI}=2.683$ $303.171)$ was determined to be an independent predictor of improvement in visual field defects caused by intracranial aneurysms that arise from the ICA. Schuss et al. ${ }^{17}$ also reported that $75 \%$ of patients who were surgically treated achieved improvement in visual symptoms in comparison with $38 \%$ of patients who received endocascular treatment. In addition, other studies reported that the only $36.8 \%$ and $50 \%$ of patients who presented with visual deficits due to intracranial aneurysms achieved improvement following endosaccular coiling. ${ }^{13,29,30}$ Therefore, we here report that it is very important to remove both aneurysmal pulsatility and mass effect in the anterior optic pathway in order to improve visual deficits.

Flow-diverting devices were recently introduced as an alternative modality for treating intracranial aneurysm. ${ }^{31-33}$ Flow-diverting devices facilitate endoluminal reconstruction of the parent artery and lead to blood flow stagnation and thrombosis in the aneurysm. ${ }^{34-36}$ These devices gradually reduce aneurysmal pulsatility and mass effect. Several studies have reported that 90\%$100 \%$ of patients who had symptomatic intracranial aneurysms either completely or partially recovered from their symptoms after treatment with flow-diverting devices. ${ }^{34,37,38}$ However, the complete occlusion rate of the flow-diverting devices for the treatment of giant ICA aneurysms is still lower than the microsurgical techniques. ${ }^{35,39,40}$ In addition, the delayed ruptures of large or giant aneurysms after treatment with flow-diversion devices have been reported. ${ }^{41,42}$ Nevertheless, flow-diverting devices may be the alternative for the treatment of symptomatic ICA aneurysm because of lower morbidity and mortality rates than traditional microsurgery, including clipping and bypass and avoiding the mass effect associated with coiling. ${ }^{35,39,40,43-45}$

\section{Visual deterioration after endosaccular coiling}

Visual symptoms are aggravated in 4 patients in group B (40\%) after endosaccular coiling. It has been reported that visual deterioration after endosaccular coiling might be caused by thromboembolic events including retinal infarction and occipital lobe infarction, which have an abrupt and maximal onset. ${ }^{13,46}$ However, we did not identify the presence of retina infarction and there was no patient who experienced occipital lobe infarction after treatment in present study. Progressive worsening of vision, which occurs hours to weeks after the procedure, may be secondary to progressive mass effect from aneurysm thrombosis and/or 
perianeurysmal inflammation and edema. ${ }^{46,47}$ Turner et al. ${ }^{46}$ reported that HydroCoil (MicroVention, Aliso Veijo, California, USA) component of the coil mass could be contributing to perianeurysmal edema and inflammation. HydroCoil is usually commonly used in our institution. Because the 4 patient experienced progressive worsening of vision, which occurred several hours after endosaccular coiling, we speculate that the causes of visual deterioration were aneurysm thrombosis and/or perianeurysmal inflammation and edema. However, these visual deteriorations did not improve satisfactorily after administration of corticosteroids.

\section{Microsurgical strategies}

The surgical exposure and dissection of an aneurysm from the anterior optic pathway that are required to perform direct clipping are difficult procedures. Sometimes, visual deficits worsen after the direct clipping of aneurysms that arise from the ICA due to surgical injury. There are 2 patients who experienced aggravated visual symptom after surgical clipping in present study. It has been reported that postoperative vision deterioration might be caused by thermal injury to the optic nerve during drilling of the bony structures, contusion of the anterior optic pathway during dissection and traction, compromised blood flow through the ophthalmic artery, and retinal ischemia due to temporary occlusion..$^{11,13,48,49}$ Therefore, we used several surgical techniques to reduce the deterioration of visual function. First, we used extradural anterior clinoidectomy rather than intradural anterior clinoidectomy. Extradural anterior clinoidectomy demonstrates several advantages over intradural anterior clinoidectomy: 1) anatomical orientation can be easily identified by dural extension into the optic canal and superior orbital fissure; 2) extradural clinoidectomy can be performed faster than intradural procedure; and 3) the dura protects the intradural structure including the optic nerve from thermal and mechanical injury. ${ }^{50,51}$ Second, we use intraoperative indocyanine green angiography after clipping. Indocyanine green angiography demonstrates several advantages, including good spatial resolution, simple dye injection, rapid performance, and the ability to morphologically and dynamically verify blood flow. ${ }^{52}$ Hence, distal flow of the ophthalmic artery can be easily verified using indocyanine green angiography during microsurgery. Third, we used the retrograde suction decompression technique when necessary, as described in previously published studies. ${ }^{53,54}$ Proximal control of large and giant aneurysms that arise from the ICA is very difficult because of their relationships with bony structures, adjacent brain structures, anterior choroidal artery, ophthalmic artery, small perforators, and optic nerves. ${ }^{54,55}$ Furthermore, even after proximally controlling the parent artery, aneurysms can still remain tensive due to their size and collateral supply. ${ }^{55}$ The retrograde suction decompression technique not only easily achieves proximal control at the cervical ICA, but can also deflate aneurysms. Hence, the retrograde suction decompression technique is useful for preventing injury to the optic nerve and ophthalmic artery.

If a large or giant aneurysm has a calcified wall, intra-aneurysmal thrombus, or if some portion of the aneurysm is located in the cavernous segment of the ICA, it may not be possible to treat the aneurysm with direct clipping. Endovascular parent artery trapping without endosaccular coiling can be a good alternative in these situations. However, ischemia-related morbidity and mortality have been reported after occlusion of the ICA. ${ }^{56,57}$ Therefore, we use balloon occlusion test before ICA trapping to identify patients at high risk of ischemic complications following ICA sacrifice. If a patient does not pass balloon test occlusion, we perform extracranial-intracranial bypass before parent artery trapping. Performing endovascular parent artery trapping on large or giant aneurysms that arise from the ICA is one of the most useful treatments because this procedure does not manipulate the optic nerve and the ophthalmic artery, and this procedure does not result in additional masses in the anterior optic pathway after treatment.

\section{Limitations}

There are several major limitations to this study. First, this study is limited by the small number of cases and its retrospective study design. Second, owing to the different skill sets and preferences of the three members of our cerebrovascular team (two neurosurgeons and one neuro-interventionist), there is inherent selection bias. Naturally, clinicians tent toward methods at which they are highly skilled. Another important limitation of this study is that the period, duration, and modality of followup after treatment were not standardized because of the diversity of patient conditions, and the different treatment modalities. In addition, the mean follow-up duration for visual field examination is relatively short.

\section{Conclusion}

Visual deficits caused by anterior optic pathway compression due to ICA aneurysms can improve after surgical clipping, endovascular parent artery trapping, and endosaccular coiling. However, based on our experiences, the treatment modality is the only predictor of improvement in visual deficits. In our present study, treatment without endosaccular coiling, including surgical clipping and endovascular trapping with or without bypass surgery, achieved visual improvement significantly more often in comparison with endosaccular coiling. Based on our 
experiences and literature reviews, we believe that removing aneurysmal mass effects in the anterior optic pathway demonstrates a major impact on improving visual deficits.

\section{References}

1. International Study of Unruptured Intracranial Aneurysms Investigators. Unruptured intracranial aneurysms--risk of rupture and risks of surgical intervention. N Engl J Med 1998;339:17251733.

2. Kim DJ, Kim DI, Lee SK, Kim SY. Unruptured aneurysms with cranial nerve symptoms: efficacy of endosaccular Guglielmi detachable coil treatment. Korean J Radiol 2003;4:141-145.

3. Jeon TY, Jeon P, Kim KH. Prevalence of unruptured intracranial aneurysm on MR angiography. Korean J Radiol 2011;12: 547-553.

4. Nam KH, Choi CH, Lee JI, Ko JG, Lee TH, Lee SW. Unruptured intracranial aneurysms with oculomotor nerve palsy: clinical outcome between surgical clipping and coil embolization. J Korean Neurosurg Soc 2010;48:109-114.

5. Hassan T, Hamimi A. Successful endovascular management of brain aneurysms presenting with mass effect and cranial nerve palsy. Neurosurg Rev 2013;36:87-97.

6. Fujiwara S, Fujii K, Nishio S, Matsushima T, Fukui M. Oculomotor nerve palsy in patients with cerebral aneurysms. Neurosurg Rev 1989;12:123-132.

7. Good EF. Ptosis as the sole manifestation of compression of the oculomotor nerve by an aneurysm of the posterior communicating artery. J Clin Neuroophthalmol 1990;10:59-61.

8. Sorimachi T, Fujii Y, Nashimoto T. A true posterior communicating artery aneurysm: variations in the relationship between the posterior communicating artery and the oculomotor nerve. Case illustration. J Neurosurg 2004;100:353.

9. Cianfoni A, Pravata E, De Blasi R, Tschuor CS, Bonaldi G. Clinical presentation of cerebral aneurysms. Eur J Radiol 2013;82: 1618-1622.

10. Date I, Asari S, Ohmoto T. Cerebral aneurysms causing visual symptoms: their features and surgical outcome. Clin Neurol Neurosurg 1998;100:259-267.

11. Nonaka T, Haraguchi K, Baba T, Koyanagi I, Houkin K. Clinical manifestations and surgical results for paraclinoid cerebral aneurysms presenting with visual symptoms. Surg Neurol 2007; 67:612-619.

12. Mendez Roberts A, Grimes AL. Enlargement of internal carotid artery aneurysm presenting with severe visual sequela: a case report and anatomy review. Optometry 2009;80:76-82.

13. Heran NS, Song JK, Kupersmith MJ, Niimi Y, Namba K, Langer DJ, et al. Large ophthalmic segment aneurysms with anterior optic pathway compression: assessment of anatomical and visual outcomes after endosaccular coil therapy. J Neurosurg 2007; 106:968-975.

14. de Oliveira JG, Borba LA, Rassi-Neto A, de Moura SM, Sanchez-Junior SL, Rassi MS, et al. Intracranial aneurysms presenting with mass effect over the anterior optic pathways: neurosurgical management and outcomes. Neurosurg Focus 2009;26:E3.

15. Rinkel GJ, Djibuti M, Algra A, van Gijn J. Prevalence and risk of rupture of intracranial aneurysms: a systematic review. Stroke 1998;29:251-256

16. Wiebers DO, Whisnant JP, Sundt TM Jr, O'Fallon WM. The significance of unruptured intracranial saccular aneurysms. $J$ Neurosurg 1987;66:23-29.

17. Schuss P, Guresir E, Berkefeld J, Seifert V, Vatter H. Influence of surgical or endovascular treatment on visual symptoms caused by intracranial aneurysms: single-center series and systematic review. J Neurosurg 2011;115:694-699.

18. Guirgis MF, Lam BL, Falcone SF. Optic tract compression from dolichoectatic basilar artery. Am J Ophthalmol 2001;132: 283-286.

19. Bakker SL, Hasan D, Bijvoet HW. Compression of the visual pathway by anterior cerebral artery aneurysm. Acta Neurol Scand 1999;99:204-207.

20. Zanini MA, Pereira VM, Jory M, Caldas JG. Giant fusiform aneurysm arising from fenestrated posterior cerebral artery and basilar tip variation: case report. Neurosurgery 2009;64:E564565.

21. Linskey ME, Sekhar LN, Horton JA, Hirsch WL Jr, Yonas H. Aneurysms of the intracavernous carotid artery: a multidisciplinary approach to treatment. J Neurosurg 1991;75:525-534.

22. Linskey ME, Sekhar LN, Hirsch W Jr, Yonas H, Horton JA. Aneurysms of the intracavernous carotid artery: clinical presentation, radiographic features, and pathogenesis. Neurosurgery 1990;26:71-79.

23. Hahn CD, Nicolle DA, Lownie SP, Drake CG. Giant cavernous carotid aneurysms: clinical presentation in fifty-seven cases. J Neuroophthalmol 2000;20:253-258.

24. Drazin D, Choulakian A, Nuno M, Gandhi R, Edgell RC, Alexander MJ. Improvement in visual symptomatology after endovascular treatment of cavernous carotid aneurysms: a multicenter study. J Vasc Interv Neurol 2013;6:15-21.

25. Ahn JY, Han IB, Kim TG, Yoon PH, Lee YJ, Lee BH, et al. Endovascular treatment of intracranial vertebral artery dissections with stent placement or stent-assisted coiling. AJNR Am J Neuroradiol 2006;27:1514-1520.

26. Kassis SZ, Jouanneau E, Tahon FB, Salkine F, Perrin G, Turjman F. Recovery of third nerve palsy after endovascular treatment of posterior communicating artery aneurysms. World 
Neurosurg 2010;73:11-16.

27. Mavilio N, Pisani R, Rivano C, Testa V, Spaziante R, Rosa M. Recovery of third nerve palsy after endovascular packing of internal carotid-posterior communicating artery aneurysms. Interv Neuroradiol 2000;6:203-209.

28. Bulsara KR, Jackson D, Galvan GM. Rate of third nerve palsy recovery following endovascular management of cerebral aneurysms. Neurosurg Rev 2007;30:307-310.

29. Malisch TW, Guglielmi G, Vinuela F, Duckwiler G, Gobin YP, Martin NA, et al. Unruptured aneurysms presenting with mass effect symptoms: response to endosaccular treatment with Guglielmi detachable coils. Part I. Symptoms of cranial nerve dysfunction. J Neurosurg 1998;89:956-961.

30. Vargas ME, Kupersmith MJ, Setton A, Nelson K, Berenstein A. Endovascular treatment of giant aneurysms which cause visual loss. Ophthalmology 1994;101:1091-1098.

31. D’Urso PI, Lanzino G, Cloft HJ, Kallmes DF. Flow diversion for intracranial aneurysms: a review. Stroke 2011;42:2363-2368.

32. Kallmes DF, Ding YH, Dai D, Kadirvel R, Lewis DA, Cloft HJ. A new endoluminal, flow-disrupting device for treatment of saccular aneurysms. Stroke 2007;38:2346-2352.

33. Pistocchi S, Blanc R, Bartolini B, Piotin M. Flow diverters at and beyond the level of the circle of willis for the treatment of intracranial aneurysms. Stroke 2012;43:1032-1038.

34. Szikora I, Berentei Z, Kulcsar Z, Marosfoi M, Vajda ZS, Lee W, et al. Treatment of intracranial aneurysms by functional reconstruction of the parent artery: the Budapest experience with the pipeline embolization device. AJNR Am J Neuroradiol 2010; 31:1139-1147.

35. Mattei TA, Ferrell AS, Britz GW. Is flow diversion the death of cerebral bypass and coiling/stent-assisted coiling for giant cavernous aneurysms? A critical review on comparative outcomes and ongoing clinical trials. Neurosurg Rev 2013;36:505-511.

36. Chalouhi N, Tjoumakaris S, Starke RM, Gonzalez LF, Randazzo C, Hasan D, et al. Comparison of flow diversion and coiling in large unruptured intracranial saccular aneurysms. Stroke 2013; 44:2150-2154

37. Szikora I, Marosfoi M, Salomvary B, Berentei Z, Gubucz I. Resolution of mass effect and compression symptoms following endoluminal flow diversion for the treatment of intracranial aneurysms. AJNR Am J Neuroradiol 2013;34:935-939.

38. Puffer RC, Piano M, Lanzino G, Valvassori L, Kallmes DF, Quilici L, et al. Treatment of cavernous sinus aneurysms with flow diversion: results in 44 patients. AJNR Am J Neuroradiol 2014;35:948-951.

39. Kim LJ, Tariq F, Levitt M, Barber J, Ghodke B, Hallam DK, et al. Multimodality treatment of complex unruptured cavernous and paraclinoid aneurysms. Neurosurgery 2014;74:51-61; dis- cussion 61; quiz 61 .

40. Piano M, Valvassori L, Quilici L, Pero G, Boccardi E. Midterm and long-term follow-up of cerebral aneurysms treated with flow diverter devices: a single-center experience. J Neurosurg 2013;118:408-416.

41. Kulcsar Z, Houdart E, Bonafe A, Parker G, Millar J, Goddard $\mathrm{AJ}$, et al. Intra-aneurysmal thrombosis as a possible cause of delayed aneurysm rupture after flow-diversion treatment. AJNR Am J Neuroradiol 2011;32:20-25.

42. Turowski B, Macht S, Kulcsar Z, Hanggi D, Stummer W. Early fatal hemorrhage after endovascular cerebral aneurysm treatment with a flow diverter (SILK-Stent): do we need to rethink our concepts? Neuroradiology 2011;53:37-41.

43. Berge J, Biondi A, Machi P, Brunel H, Pierot L, Gabrillargues J, et al. Flow-diverter silk stent for the treatment of intracranial aneurysms: 1-year follow-up in a multicenter study. AJNR Am J Neuroradiol 2012;33:1150-1155.

44. Fargen KM, Velat GJ, Lawson MF, Mocco J, Hoh BL. Review of reported complications associated with the Pipeline Embolization Device. World Neurosurg 2012;77:403-404.

45. Cantore G, Santoro A, Guidetti G, Delfinis CP, Colonnese C, Passacantilli E. Surgical treatment of giant intracranial aneurysms: current viewpoint. Neurosurgery 2008;63:279-289.

46. Turner RD, Byrne JV, Kelly ME, Mitsos AP, Gonugunta V, Lalloo $S$, et al. Delayed visual deficits and monocular blindness after endovascular treatment of large and giant paraophthalmic aneurysms. Neurosurgery 2008;63:469-474.

47. Schmidt GW, Oster SF, Golnik KC, Tumialan LM, Biousse V, Turbin $\mathrm{R}$, et al. Isolated progressive visual loss after coiling of paraclinoid aneurysms. AJNR Am J Neuroradiol 2007;28: 1882-1889.

48. Rizzo JF 3rd. Visual loss after neurosurgical repair of paraclinoid aneurysms. Ophthalmology 1995; 102:905-910.

49. Fox JL. Microsurgical treatment of ventral (paraclinoid) internal carotid artery aneurysms. Neurosurgery 1988;22:32-39.

50. Yonekawa Y, Ogata N, Imhof HG, Olivecrona M, Strommer K, Kwak TE, et al. Selective extradural anterior clinoidectomy for supra- and parasellar processes. Technical note. J Neurosurg 1997;87:636-642.

51. Yang Y, Wang H, Shao Y, Wei Z, Zhu S, Wang J. Extradural anterior clinoidectomy as an alternative approach for optic nerve decompression: anatomic study and clinical experience. Neurosurgery 2006;59(Suppl 2):ONS253-262.

52. Bacigaluppi S, Fontanella M, Manninen P, Ducati A, Tredici G, Gentili F. Monitoring techniques for prevention of procedurerelated ischemic damage in aneurysm surgery. World Neurosurg 2012;78:276-288.

53. Fan YW, Chan KH, Lui WM, Hung KN. Retrograde suction 
decompression of paraclinoid aneurysm--a revised technique. Surg Neurol 1999;51:129-131.

54. Mattingly T, Kole MK, Nicolle D, Boulton M, Pelz D, Lownie SP. Visual outcomes for surgical treatment of large and giant carotid ophthalmic segment aneurysms: a case series utilizing retrograde suction decompression (the "Dallas technique"). $J$ Neurosurg 2013;118:937-946.

55. Chen SF, Kato Y, Subramanian B, Kumar A, Watabe T, Imizu $\mathrm{S}$, et al. Retrograde suction decompression assisted clipping of large and giant cerebral aneurysms: our experience. Minim Invasive Neurosurg 2011;54:1-4.

56. Larson JJ, Tew JM Jr, Tomsick TA, van Loveren HR. Treatment of aneurysms of the internal carotid artery by intravascular balloon occlusion: long-term follow-up of 58 patients. Neurosurgery 1995;36:26-30.

57. Roski RA, Spetzler RF, Nulsen FE. Late complications of carotid ligation in the treatment of intracranial aneurysms. J Neurosurg 1981;54:583-587. 